\title{
Presentism and Actualism
}

\author{
Harold W. Noonan ${ }^{1}$
}

Received: 28 January 2018 / Accepted: 12 June 2018 /

Published online: 27 June 2018

(C) The Author(s) 2018

\begin{abstract}
Presentism, some say, is either the analytic triviality that the only things that exist now are ones that exist now or the obviously false claim that the only things that have ever existed or will are ones that exist now. I argue that the correct understanding of presentism is the latter and so understood the claim is not obviously false. To appreciate this one has to see presentism as strictly analogous to anti-Lewisean actualism. What this modal analogue makes evident is that singular tensed statements can have scope ambiguities and so can be thought of as true with the temporal operator represented by the tense read as having wide scope. Secondly, I argue that the analogy with the modal case also makes it clear that presentism must be understood as a thesis of the form: 'the only things that have ever existed or ever will exist stand in relation $\mathrm{R}$ to this (present) utterance', and is not a substantive topic for debate until relation $\mathrm{R}$ is characterized in non-temporal terms. However, despite the strict analogy, I argue that presentism may be a harder position to defend than actualism, since the truth-maker objection, properly interpreted, with Lewis, as based on a supervenience thesis, has more force as an objection to presentism since supervenience is itself a modal notion.
\end{abstract}

Keywords Presentism $\cdot$ Actualism $\cdot$ Prior $\cdot$ Lewis $\cdot$ Scope

\section{I}

Several philosophers have argued that the debate in the philosophy of time between presentists and their opponents is not a substantive one. Presentism, they argue, is either an analytic triviality or obviously false (see, for this controversy, Crisp 2003, 2004a, b, Lombard 2010, Ludlow 2004, Meyer 2005, 2013a, b, Noonan 2013, Stoneham 2009). Either way there can be no interesting philosophical dispute. I shall first argue that this is mistaken. There is an understanding of presentism on which it is neither trivial nor obviously false. So understood it is strictly analogous to actualism (explained below), whilst its denial is strictly analogous to possibilism (explained below). The key to

Harold W. Noonan

Harold.noonan@nottingham.ac.uk

1 Department of Philosophy, University of Nottingham, Nottingham, UK 
understanding the possibility of a non-trivial but not obviously false reading of presentism is to recognise that singular tensed statements can have scope ambiguities and so can be thought of as true with the temporal operator represented by the tense read as having wide scope, but false with it interpreted as having narrow scope. It is this possibility that the modal analogue makes evident. ${ }^{1}$

Secondly, I shall argue that the analogy with the modal case makes it clear that presentism must be understood as a thesis of the form: 'the only things that have ever existed or ever will exist stand in relation $\mathrm{R}$ to this (present) utterance', and is not a substantive topic for debate until relation $\mathrm{R}$ is characterized in non-temporal terms.

Thirdly, I shall argue that, despite the strict analogy, presentism may be a harder position to defend than actualism, and in particular that the truth-maker objection has more force as an objection to presentism than to actualism.

\section{II}

Presentism is typically stated as the thesis that only the present exists, or that only presently existing objects exist (leaving abstract objects aside). Its denial is the thesis that there are non-present objects (in addition to abstract objects, if any). More illuminatingly expressed (and without the need for parenthetical qualifications), I suggest, presentism should be formulated as the thesis that the only objects that have ever existed are ones that exist now and that the only objects that ever will exist are ones that exist now. Its denial is then the thesis that some objects that have existed exist no longer or some objects that will exist do not exist yet. In the literature other theses are discussed. The growing block thesis can be understood as the thesis that some objects that have existed no longer exist but that no objects that will exist do not exist now. Eternalism can be understood as the thesis that some objects have existed that do not exist anymore and some objects that will exist do not exist yet. More strongly it can be understood as claiming that for every $\mathrm{n}$ some objects existed $\mathrm{n}$ units of time ago but do not exist now and some objects will exist $\mathrm{n}$ units of time from now that do not exist now.

These are ontological theses. Presentism is generally regarded as being a dynamic theory of time, involving the idea that time flows or passes. I shall only be concerned with presentism as an ontological thesis. But I shall say a little about the dynamic thesis here. The time of my breakfast has passed a further hour into the past in the last hour, since an hour has elapsed since an hour ago and now. An hour ago it was the case that I ate three hours previously, but it is not now the case that I ate three hours previously. The schema 'It was the case that $\mathrm{p}$ but it is not now the case that p' is satisfied. That there are true instances of this schema is, I think all that the thesis that time flows or passes comes to (Prior 1968: 14, see also Prior 1958)). I do not say that it is an illusion that time passes. 'It is an illusion that time passes' is a meaningful form of words only if 'time passes' is meaningful (just as 'it is an illusion that there could be something further north than the North Pole' is meaningful only if 'there could be something further north than the North Pole' is meaningful). If 'time passes' has the meaning suggested it is meaningful, but then it is no illusion that time passes since there are true instances of the schema. If 'time

\footnotetext{
${ }^{1}$ The presentism I am discussing is Priorean presentism, 'the present simply is the real considered in relation to two species of unreality, namely the past and future' (Prior 1970: 145; see also Percival 2002, especially section 3). The aim of the first part of this paper is to show that this is the strict temporal analogue of the view of modality which most of us, pace Lewis, take for granted, that is, as Percival puts it, that 'the actual is the real considered in relation to one species of unreality, namely the (merely) possible' (Percival 2002:106).
} 
passes' does not mean this, I think, it is meaningless, as then is 'It is an illusion that time passes', so again it is not true that it is an illusion that time passes.

Sceptics about the substantiality of the debate about presentism considered as an ontological thesis pose a dilemma. They say that presentism, as originally stated, means either that only presently existing objects exist now, in which case it is trivial, or that only presently existing objects ever have existed or ever will exist, in which case it is obviously false. Some philosophers have defended the substantiality of the debate by resorting to a tenseless notion of existence, existence simpliciter, or being something ( $\mathrm{y}$ is something iff for some $\mathrm{x}, \mathrm{x}=\mathrm{y}$ ). They have defined presentism as the thesis that only things that exist now exist simpliciter. But this cannot help. Existence simpliciter is a more general notion of existence, applicable not only to all temporal objects, but also to atemporal objects like numbers, if there are any. But presentists and their opponents can agree that number exist simpliciter and do not exist now since they exist only atemporally - their disagreement only concerns what exist in time. Anyway, if only presently existing objects exist simpliciter only presently existing objects have existed or will exist since any objects that have existed or will exist exist simpliciter (since any object whatsoever exists simpliciter - is something). So if it is obviously false that only presently existing objects have existed or will exist it is likewise obviously false that only presently existing objects exist simpliciter. What the defender of the debate must do is to defend the claim that presentism, understood as the thesis that only presently existing objects have existed or will exist, is not obviously false.

Of course, the thesis that every kind of thing there ever was or ever will be has instances now is obviously false. But this can be admitted by everyone. The presentist agrees that there used to be dinosaurs though no animal of that kind exists now. What the presentist must defend is the thesis that every individual object that has ever existed or will exist exists now. This is what cannot be obviously false if the debate is to be a substantive one.

But it may seem that, just as it is obviously false that every kind of thing there ever was or ever will be has instances now, so it is obviously false that that every individual that has ever existed or will exist exists now, since Caesar no longer exists but used to. But the presentist must say that 'Caesar used to exist' has two readings, one in which the name is given narrow scope, which is the only one we hear and is true, and one in which the name is given wide scope and is false.

Compare, 'the present king of France does not exist'. From a Russellian viewpoint the description can have wide or narrow scope (wide: 'there is a present $\mathrm{KoF}$ and he doesn't exist'; narrow: 'it is not the case that there exists a present KoF'). With the description given wide scope it is false. On the narrow scope reading it is true. But plausibly we only hear the narrow scope reading. Comparably, the presentist must say, 'Caesar once existed' is true on a narrow scope reading of the name, but false on a wide scope reading. On our everyday understanding it is simply true that Caesar once existed. We do not hear the ambiguity. Nevertheless, the presentist must say, the ambiguity exists. So names of past entities are in fact, like descriptions, not scopeindifferent in temporal contexts.

Of course, the presentist must say that the same is true of names of future entities (or would be if we had any), which seems to my common-sense far easier to accept (this is a point in favour of the Growing Block). This goes with the thought that future facts are general except when they involve presently existing entities. It is a fact that Obama will 
write a romantic novel, or it is a fact that he will not. Whichever is the case the fact in question is not purely general. But the fact, assuming it to be such, that in 3000 A.D. the ruler of Britain will write a romantic novel, is a purely general fact (Prior 1968: 143). This, I think, is common sense, and is in accord with the presentist's (and the growing blocker's) thought that every individual that ever will exist exists now, so that if we use 'Boadicea II' as the name of the then ruler of Brtiain, the reading of 'In 3000 A.D. Boadicea II will write a romantic novel', with the name given wide scope, has to be false.

Where the presentist, but not the growing blocker, departs from common sense, I think, is in thinking of the past in the same way, that is, in thinking of past facts as purely general except when they concern presently existing entities (Prior 1968: 13 and 143 ). But that is his position, and it is not so obviously false that we can simply dismiss the debate as philosophical insignificant.

\section{III}

To be clearer about the options for, and the obligations of, presentism the comparison with actualism is instructive.

Actualism is the thesis that only actual objects exist. It might be questioned whether there can be a substantive debate about this. For what does 'exist' mean? If the thesis means that only actual objects actually exist it is an analytic triviality. Whilst if it means that only actual objects could have existed, it may be said, it is obviously false since there could have been talking donkeys. It is no help to the defender of the substantiality of the debate to suggest that in the statement of actualism 'exist' means 'exist simpliciter' since any objects that could have existed exist simpliciter (since any objects whatsoever exist simpliciter). So if it is obviously false that only actual objects could have existed, that every object that could have existed actually exists, it is obviously false that only actual objects exist simpliciter, that every object that exists simpliciter actually exists. The actualist, or the defender of the substantiality of the debate, must say that it is not obviously false that every individual object that could have existed actually exists. In fact, the actualist must say, it is true.

It is, of course, obviously false that every kind of thing that could have existed has actual instances. But this obviously false second-order claim should be distinguished from the first-order claim the actualist needs to defend. It may be objected that this firstorder claim is still obviously false, since the present king of France could have existed, but does not actually exist. But the reply now is that this is only so if the description in the statement 'the present king of France could have existed' is read as having narrow scope; when it is given wide scope the proposition that the present king of France could have existed is false, though we do not hear the reading with the description having wide scope. ${ }^{2}$

\footnotetext{
${ }^{2}$ Of course, the actualist will agree with the possibilist that there is (actually) someone who could have been the present King of France, for example, Donald Trump, just as the presentist will agree with his opponent that there is (now) someone (Barack Obama) who was once the Democratic US President. So to get an example which is strictly analogous to the one used in the discussion of the temporal case above (the long-dead Caesar) we need another description, say 'the king of the talking donkeys'. The possibilist and actualist will disagree about the truth-value of 'there is something which could have been the king of the talking donkeys' despite agreeing that it could have been that there was such a thing as the king of the talking donkeys, just as the opponent of presentism and the presentist will disagree about the truth-value of 'there is someone who was once Julius Caesar' (since the actualist will say that nothing (actual) could have been a talking donkey at all).
} 
The debate between the actualist and the possibilist thus far is precisely analogous to that between the presentist and his opponent.

\section{IV}

Our focus just now has been on the objection to actualism, understood as the thesis that everything that could have existed actually exists, that it makes actualism obviously false and possibilism obviously true. We have just considered and rejected this objection. Another objection is that it makes actualism trivially true and possibilism obviously false. This is so if 'actually exists' means 'is identical with something', 'exists simpliciter', since every object that could have existed is identical with something (since every object that is anything is identical with something). Actualism is thus trivially true, a logical truth, and possibilism a contradiction, unless 'actually exists' means something more restrictive than 'exists' in the sense of 'is identical with something'.

Now, of course, according to Lewis (1986), 'actually exists' does mean something more restrictive. 'Is actual' means 'is spatiotemporally related to this utterance'. ${ }^{3}$ Its meaning is indexical. So the thesis that only actual objects could have existed is a clearly non-trivial thesis if understood in these terms. Possibilism, the thesis that some objects that could have existed do not actually exist, is correspondingly not trivially false. In fact, Lewis is a possibilist, in this sense. Since he thinks that some objects (e.g., talking donkeys) exist that are not spatiotemporally related to this utterance (and are not actual 'by courtesy'), a fortiori, of course, he thinks that some objects that could have existed are not spatiotemporally related to this utterance nor are actual 'by courtesy'. 4

So a possibilist must understand 'is actual' as meaning something other than 'is identical with something', otherwise possibilism is self-contradictory.

Now it is highly controversial that 'actually' has the specific meaning Lewis ascribes to it, or has an indexical meaning at all. ${ }^{5}$ It is very tempting to think that actually 'actually' just means about the same as 'in fact ${ }^{6}$ and if, in fact, this is the case actualism just is a logical truth and possibilism is actually a contradiction. If so Lewisean modal realism is not appropriately thought of as a version of possibilism.

However, whether this is so is not a question we need to consider. It is Lewisean possibilism, rightly so-called or not, which is relevant to our discussion since it is

\footnotetext{
${ }^{3}$ Or, by courtesy, 'exists from the standpoint of the world of this utterance' (like numbers) (1986: 96).

${ }^{4}$ But can the dispute between the Lewisean possibilist and the actualist not be characterized more simply? Don't they disagree about whether there are (quantifier wide-open) (things that could have been) talking donkeys? Not necessarily. I am no Lewisean but I am not prepared to deny that there are talking donkeys. It is a big and strange (spatiotemporally connected) universe out there. Maybe there are talking donkeys somewhere. Nor, if I were a friend of Lewis, would I be obliged to believe in talking donkeys. Lewis does but that is because he thinks that there could be talking donkeys. One might be a genuine modal realist without Lewis's common-sense and disagree. For the same reasons the dispute between the presentist and his opponent cannot be characterized as disagreement over whether there are (things that are/were/will be) dinosaurs.

${ }^{5}$ Of course, though the anti-Lewisean actualist must use 'actual' with the indexical meaning Lewis gives it to state his position, he will say that the actual world can be identified non-indexically, as the only (Lewisean) world. Just so, if I am a solipsist I will say that I can be identified non-indexically, as the only person, and if a narcissist I will say that I can be identified non-indexically, as the prettiest person. Similarly, the presentist will say that the present time can be identified non-indexically as the only time, and the growing blocker will say that the present time can be identified non-indexically as the latest time.

6 "“Really", "actually", "in fact", "in the real world" are strictly redundant expressions - that, and not any prejudice or provincialism, is their specialness' (Prior 1970: 246).
} 
uncontroversial that 'presently exists' does not just mean 'exists' in the sense of 'is identical with something', otherwise 'only what presently exists exists' would be trivially true whatever the second occurrence of 'exists' in it means. (Of course, Lewisean possibilism, the thesis that some things that could have existed are not spatiotemporally related to this utterance nor actual 'by courtesy', remains a substantive these, however we classify it). So it is the thesis of Lewisian possibilism, whether or not aptly so-called, which is strictly analogous to the rejection of presentism. Presentism must then be understood as a thesis of the following form: everything that ever has existed or ever will exist stands in relation $\mathrm{R}$ to this utterance. Of course, this is obvious. Presentism is the thesis that everything that ever has existed and ever will exist exists now, and 'now' is an indexical meaning 'simultaneous with this utterance'. But what the analogy with the modal case brings out is that presentism is not a substantive topic for debate until relation $\mathrm{R}$ is characterized in non-temporal terms. There is no substantive issue between the Lewisean possibilist and his opponent if he says merely that there are things that (could have) exist(ed) that are not located in the possible world containing this utterance, and his opponent denies this - but no non-modal explanation ${ }^{7}$ of the notion of 'being in the possible world in which this utterance is located' is agreed. Mutatis mutandis, there is no genuine debate between the opponent of presentism and the presentist if the former says merely that there are things that used to exist or will exist that are not in existence at the time of occurrence of this utterance, and the latter denies this - but no non-temporal ${ }^{8}$ explanation of 'existing at the time of this utterance' is agreed.

Different specifications of relation $\mathrm{R}$ yield different understandings of presentism (Hinchliff 2000; Savitt 2000). One may specify R to be identity. This yields point presentism, the thesis that reality is constituted by the here-now and lies within the location of at most one person (Hinchliff 2000; Stein 1991). The point-presentist will of course say that there used to be dinosaurs and that Caesar crossed the Rubicon, and by the same token, that elsewhere there are skyscrapers and Obama is the US President (I write in 2016, in Britain). So he will deny that his position amounts to solipsism of the present moment. The interpretation of $\mathrm{R}$ as identity yields a doctrine consistent with special relativity, and is also consistent with simultaneity being an equivalence relation. It may be the best understanding of presentism consistent with modern physics. One may also specify $\mathrm{R}$ as space-like relatedness (Weingard 1972). This allows for a spatially and extended present at the cost of abandoning the transitivity of simultaneity. It allows the present to include four-dimensional, temporally extended chunks of spacetime containing the entire lives of distant organisms. This has been called bowtie presentism (Gilmore et al. 2016). Or R can be specified as light-like relatedness (Godfrey-Smith 1979; Hinchliff 2000) so the present can include the entire career of

\footnotetext{
${ }^{7}$ No explanation which does not employ modal operators. The actualist can employ modal operators to give senses to ' $\mathrm{x}$ is a possible world', ' $\mathrm{x}$ is the actual world' and ' $\mathrm{x}$ is in world w' (and hence to ' $\mathrm{x}$ is in some world' and ' $x$ could have existed') and so give a non-Lewisean sense to the sentence 'everything that could have existed exists in the actual world' (Plantinga 1974). The proposition expressed by the sentence so understood will be true, but it will be acceptable to the Lewisean, too, so his endorsement of it will not be what makes the actualist an actualist. (In fact, Plantinga (Plantinga 1983: 3) defines actualism as the thesis that necessarily everything exists, which of course Lewis accepts, but Plantinga notes that this thesis is wrongly so-called and should have been called 'existentialism' - but he has already used that word for another thesis.)

${ }^{8}$ No explanation which does not involve temporal operators.
} 
a photon that travels across the universe at light speed. This yields cone presentism, according to which, again, simultaneity is not an equivalence relation. ${ }^{9}$

Interpreted in line with one of these readings of $\mathrm{R}$ the debate about presentism includes both factual and conceptual questions. This is precisely analogous to what is the case in the debate about actualism, interpreted as suggested above (see also fn.4). It is only because Lewis is such a common-sense sort of chap, who thinks, like most of us, that possibility extends beyond the actual, as well as a philosopher with an analysis of modality, that he commits himself to a plurality of spatio-temporally separated cosmoi. One could accept the analysis but reject the ontology by denying that there are as many possibilities as Lewis and most of us think. So there is a purely conceptual issue to be debated: does the proposition that there could have been talking donkeys, though nothing which actually exists could have been one, entail that something which could have been a talking donkey exists in spatio-temporal separation from us (as the Lewisean analysis implies)? Similarly, in the debate about presentism, conceived as above, there is a purely conceptual issue: does the proposition that there were once dinosaurs, though nothing now existent was once a dinosaur, entail that something which was once a dinosaur is R-separated from this utterance? Whether there are things $\mathrm{R}$-separated from this utterance is another, factual, question.

\section{$V$}

One of the most frequently discussed objections to presentism is the truth-making, or grounding, objection (Crisp 2007; Keller 2004). Cutting to the chase, and following Lewis (2001), since the demand for a truth-maker can easily be dismissed, this is best understood as an objection to presentism based on a supervenience thesis in which neither the notion of a truth-maker nor that of truth need figure (see also Asay and Baron (2014)). The supervenience thesis is that what is the case (what is actually the case, what could be the case, what is now the case, what was the case and what will be the case) supervenes on what there is and is not and how the things that there are are. ${ }^{10}$ According to the presentist this is equivalent to the thesis that what is the case supervenes on what there is and is not now, i.e., what there is and is not R-related to this utterance, and how the things that are R-related to this utterance (fundamentally) are (for the chosen reading of ' $R$ '). But it is the case that there were dinosaurs, so the presentist must either reject the supervenience thesis or explain how whether there were dinosaurs so supervenes. The difficulty for the presentist is that it seems implausible that a full description of how things are now provides a supervenience basis for the past, at least if the description is only in present-tense terms. It appears to be not merely an epistemic possibility that the world came into existence five minutes ago complete with fossils and so on. So the presentist is either forced to reject the supervenience thesis or to claim that a complete description of present reality must make use of the past tense (e.g., saying of the world that it once contained dinosaurs).

It may be thought that if this grounding objection is a problem for the presentist it must equally be a problem for the anti-Lewisean actualist. But the cases are

\footnotetext{
${ }^{9}$ In Galilean space-time simultaneity may be defined as spatial relatedness. In Newtonian absolute space and time simultaneous events can only be defined as events which are causally connected but by no finitely fast signal.

${ }^{10}$ That is, what their properties and relations are (Lewis adds the qualification 'fundamental').
} 
disanalogous since supervenience is a modal notion. So it is not clearly true that whether there could have been talking donkeys is not supervenient on how things actually are. It is not clearly true that, given how things actually are, it is left open whether there could have been talking donkeys, as, at least prima facie, given how things are now, it is left open whether the world came into existence five minutes, replete with dinosaur fossils and so on. ${ }^{11}$

For this and perhaps other reasons presentism looks to be a harder position to defend than anti-Lewisean actualism.

\section{$V I$}

My main aim has been to argue that as formulated above presentism is neither trivially true not obviously false. I have argued that to appreciate this it is necessary to recognise scope distinctions in past and future tense singular statements, and that the appropriate modal analogue of presentism is not actualism in general but anti-Lewisean actualism, whether or not properly so-called. I have also argued that presentism only has a definite content if the notion of the present is specified in non-temporal terms. The analogy here is to the way in which the (putatively) indexical notion of the actual is understood in non-modal terms in the debate between the Lewisean possibilist and his opponent. Finally, I have argued that, particularly with reference to the truth-making objection, presentism, despite the analogy, seems more difficult to defend than actualism, because the truth-making objection is best understood as an objection based on a supervenience thesis, and supervenience is a modal notion.

Open Access This article is distributed under the terms of the Creative Commons Attribution 4.0 International License (http://creativecommons.org/licenses/by/4.0/), which permits unrestricted use, distribution, and reproduction in any medium, provided you give appropriate credit to the original author(s) and the source, provide a link to the Creative Commons license, and indicate if changes were made.

\section{References}

Asay, J., \& Baron, S. (2014). The Hard Road to Presentism. Pacific Philosophical Quarterly, 95(3), 314-335. Crisp, T. M. (2003). Presentism. In M. J. Loux \& D. W. Zimmerman (Eds.), The Oxford handbook of metaphysics (pp. 211-245). Oxford: Oxford University Press.

Crisp, T. M. (2004a). On presentism and triviality. In D. W. Zimmerman (Ed.), Oxford studies in metaphysics (Vol. 1, pp. 15-20). Oxford: Clarendon.

Crisp, T. M. (2004b). Reply to Ludlow. In D. W. Zimmerman (Ed.), Oxford studies in metaphysics (Vol. 1, pp. 37-46). Oxford: Clarendon.

Crisp, T. M. (2007). Presentism and the grounding objection. Noûs, 41, 90-109.

Gilmore, C., Costa, D., \& Calosi, C. (2016). Relativity and three four-dimensionalisms. Philosophy Compass, $11,102-120$.

Godfrey-Smith, W. (1979). Special relativity and the present. Philosophical Studies, 36, 233-244.

\footnotetext{
${ }^{11}$ So what can the presentist say to the argument? I think that he must simply deny the supervenience claim and insist that reality can only be fully described in a language containing irreducible temporal operators. But the supervenience claim is not just a thesis of Lewis's, it encapsulates a vision going back to Quine and indeed Frege, expressed by Wittgenstein in the Tractatus: 'The world is all that is the case. The world is the totality of facts not of things. What is the case - a fact - is the existence of states of affairs. A state of affairs (a state of things) is a combination of objects (things).'
} 
Hinchliff, M. (2000). A defense of presentism in a relativistic setting. Philosophy of Science, 67(Sep., 2000), S575-S586.

Keller, S. (2004). Presentism and truthmaking. In D. W. Zimmerman (Ed.), Oxford studies in metaphysics (Vol. 1, pp. 83-104). Oxford: Clarendon.

Lewis, D. (1986). On the plurality of worlds. Oxford: Blackwell.

Lewis, D. (2001). Truthmaking and difference-making. Nô̂s, 35(4), 602-615.

Lombard, L. B. (2010). Time for a change: A polemic against the presentism-eternalism debate. In J. C. Campbell, M. O’Rourke, \& H. S. Silverstein (Eds.), Time and identity (pp. 49-78). Cambridge, Mass: MIT Press.

Ludlow, P. (2004). Presentism, triviality, and the varieties of tensism. In D. W. Zimmerman (Ed.), Oxford studies in metaphysics (Vol. 1, pp. 21-36). Oxford: Clarendon.

Meyer, U. (2005). The presentist's dilemma. Philosophical Studies, 122, 213-225.

Meyer, U. (2013a). The nature of time. Oxford: Clarendon.

Meyer, U. (2013b). The triviality of presentism. In R. Ciuni, K. Miller, \& G. Torrengo (Eds.), New papers on the present (pp. 67-87). Philosophia Verlag: Munich.

Noonan, H. (2013). Presentism and eternalism. Erkenntnis, 78, 219-227.

Percival, P. (2002). A presentist's refutation of Mellor's McTaggart. Royal Institute of Philosophy Supplement, 50, 91-118.

Plantinga, A. (1974). The nature of necessity. Oxford: Clarendon Press.

Plantinga, A. (1983). On Existentialism. Philosophical Studies, 44, 1-20.

Prior, A. N. (1958). Time after time. Mind, 67, 242-246.

Prior, A. N. (1968). Papers on time and tense. Oxford: Clarendon Press.

Prior, A. N. (1970). The notion of the present. Studium Generale, 23, 245-248.

Savitt, S. (2000). There's no time like the present (in Minkowski Spacetime). Philosophy of Science, 67(Proceedings), S563-S574.

Stein, H. (1991). On relativity theory and the openness of the future. Philosophy of Science, 58, 147-167.

Stoneham, T. (2009). Time and truth: The presentism and eternalism debate. Philosophy, 84, 201-218.

Weingard, R. (1972). Relativity and the reality of past and future events. British Journal for the Philosophy of Science, 23(2), 119-121. 